\begin{tabular}{|l|l|}
\hline $\begin{array}{l}\text { EUROPEAN } \\
\text { PUBLIC \& SOCIAL } \\
\text { INNOVATION }\end{array}$ & $\begin{array}{l}\text { European Public \& Social Innovation Review (EPSIR), Vol 2 (1), 2017, ISSN 2529-9824 } \\
\text { Julia M. Wittmayer, Bonno Pel, Tom Bauler \& Flor Avelino. } \\
\text { REVIEW }\end{array}$ \\
\hline C Sinnergiak, Some Rights Reserved (cc) EY-NG-ND & Creative Commons 4.0 International \\
\hline
\end{tabular}

\title{
EDITORIAL SYNTHESIS: METHODOLOGICAL CHALLENGES IN SOCIAL INNOVATION RESEARCH
}

\author{
Julia M. Wittmayer ${ }^{1 *}$, Bonno Pel${ }^{2}$, Tom Bauler ${ }^{2}$, Flor Avelino' \\ *corresponding author: wittmayer@drift.eur.nl \\ ${ }^{1}$ DRIFT, Erasmus University Rotterdam, The Netherlands \\ ${ }^{2}$ Université Libre de Bruxelles, Belgium
}

\section{KEY WORDS}

Social innovation

Methodology,

Logics of inquiry

Systematic knowledge

development

Action-oriented research

Temporality

Comparative research

Axiological standpoint

\section{ABSTRACT}

In recent years, there have been substantial efforts towards theory-building and conceptual clarification in social innovation (SI) research further contributing to its consolidation as a research field. Taking a different angle, this special issue aims to contribute to such consolidation by introducing greater reflexivity about the underlying methodologies and logics of inquiry. It features eight contributions from the main methodological orientations in SI research, namely systematic knowledge development and action-oriented research that discuss particular methodological challenges and advances. This editorial synthesis serves to take stock and elicit their broader significance for SI research along the normative, temporal and comparative dimensions of methodology choices. Dimensions, which are salient to SI research without being tied to any specific methodological tradition. As such, they reflect our aim to transcend the methodological fragmentation of the SI research field and open up a methodological discussion through a methodologically pluralist stance.

\section{Challenges of method for a consolidating research field}

In recent years, social innovation (SI) is rapidly growing as a field of research and praxis. The fast growth is also met with doubts and scepticism about its scientific and societal significance. As a fashionable and ambiguous policy concept, it is vulnerable to ending up as a passing 'hype' (Pol \& Ville 2009). Moreover, the unmistakeable ideological dimensions of the SI concept (Cf. Jessop et al. 2013, Edwards-Schachter \& Wallace 2017) give further reason to doubt its sustained relevance for research. 
The various critical accounts of the SI concept also originate from proponents, who are typically concerned with the consolidation of SI as an emergent field of research (e.g. CajaibaSantana 2014, Larsson and Brandsen 2016, Moulaert et al. 2017). In these rather critical-affirmative accounts, the concept is appreciated for several reasons. First, as stressed by Franz et al. (2012), the concept is deemed necessary for the emancipation and legitimacy of the progressive, inventive and constructive innovation efforts of various SI initiatives. These merit societal recognition no less than the much celebrated technological innovations. Second, SI is a concept with boundary-object qualities. It helps to organize interdisciplinary and transdisciplinary collaboration between researchers and practitioners of different backgrounds (Moulaert 2010, Osburg \& Schmidpeter 2013, Edwards-Schachter \& Wallace 2017). Third, SI has become an influential 'knowing of governance' (Voß \& Freeman 2016), a pervasive framing of outlooks on political life that as such merits serious scientific attention: SI is increasingly considered as one of the main governance modes through which to undertake societal change (Schubert 2017).

When considering the rise of SI as part of a broader shift towards an 'innovation society', the consolidation as a research field appears as a quite inevitable next move. This consolidation has often been described along the diagnosis by Mulgan (2006), who calls for theoretical advances to 'catch up with practice'. In this regard, there have been substantial efforts towards theory-building and conceptual clarification, of which numerous EU-funded research projects (European Commission 2013, Moulaert et al. 2017) are witness. In addition, attempts towards conceptual clarification proliferate, charting the history, semantic dimensions and disciplinary affiliations of the SI concept (Cajaiba-Santana 2014, Ayob et al. 2016, Van der Have \& Rupacalba 2016, Edwards-Schachter \& Wallace 2017, Marques et al. 2017).

This special issue aims to support this consolidation process by introducing greater reflexivity about the underlying methodologies and logics of inquiry in SI research. Innovation studies in general appear to be quite limited in this respect, with a rather sustained reliance on either quantitative indicator-based research or ethnographic single case studies (Jungmann et al. 2015). Similar remarks about the limited methodological scope have been made about SI research with its largely taken-for-granted research designs of 'unique case' and 'few-case comparison' (Mulgan 2006, Murray et al. 2010, Schröder et al. 2014). This is not to deny various methodological advances made. There is a striking divergence, however. Whilst some advances are strongly driven by aims of sound science and systematic knowledge development (Martinelli et al. 2010, Bouchard \& Trudelle 2013, El-Haddadeh et al. 2014, McGowan \& Westley 2015, Pelka \& Terstriep 2016), others rather seek to develop modes of action-oriented investigation (Moulaert \& van Dyck 2013, Novy et al. 2013, Moulaert et al. 2017). In other words, recent advances in SI methodology are departing from quite different logics of inquiry and understandings of scientific knowledge production. When seeking to methodologically solidify SI research, this emerging methodological fragmentation needs to be tackled as well. 
The answer to the above fragmentation tendencies does not necessarily reside in standardization, however. Such an approach would not only neglect how SI research is fed by different research traditions (Van der Have \& Rupacalba 2016), but would also be out of tune with the still far from stabilized theoretical understanding. This special issue therefore starts from a methodologically pluralistic stance, and is committed more to consequential reasoning and coherent logics of inquiry than to adhesion to standard methods (Blatter \& Haverland 2012). Focusing on the broader issue of research design and logics of inquiry, the search for rigour in methodology is undertaken in full acknowledgement of the diversity of SI understandings and knowledge interests. In line with Ulrich (2003), our method pluralism moves 'beyond methodology', and situates method choices within the broader process of knowledge construction.

This special issue builds on the proceedings of a workshop held in February 2017. For this workshop, leading SI scholars from different research backgrounds were invited to identify methodological challenges and corresponding advances in SI research. Even if not comprising the full range of methodologies relevant to SI research - especially the various quantitative approaches would have made for valuable complements - this special issue presents a diverse sample of methodological challenges and methodological advances (see Table 1 below). In order to make these insights relevant beyond the particular research endeavour, all contributions situate their logics of inquiry in broader methodological discussions. Seizing this opportunity to draw broader implications for SI research, our synthesis is driven by two basic questions: What are the main methodological challenges in SI research, and how can they be addressed? The answers to these questions are developed in the form of three transversal themes. As these themes transcend the aforementioned divide between systematic knowledge development and reflective action-oriented research, they are arguably pertinent to the methodological reflection in SI research more broadly. After subsequently addressing the normative (Section 2), the temporal (Section 3) and the comparative (section 4) dimensions of methodology choices, we answer our research questions and draw out broader implications for SI research (Section 5).

Table 1: Overview of contributions

\begin{tabular}{l|l|l}
\hline$\#$ & Author(s) & Title \\
\hline 1 & Gerald Taylor Aiken & $\begin{array}{l}\text { Social Innovation and Participatory Action Research: A way to } \\
\text { research community? }\end{array}$ \\
\hline 2 & Kees Biekart & $\begin{array}{l}\text { Contributing to Civic Innovation through Participatory Action } \\
\text { Research }\end{array}$ \\
\hline 3 & $\begin{array}{l}\text { Ela Callorda Fossati, Florence Degavre, } \\
\text { Marthe Nyssens }\end{array}$ & $\begin{array}{l}\text { How to deal with an "essentially contested concept" on the field? } \\
\text { Sampling social innovations through the Delphi method }\end{array}$ \\
\hline
\end{tabular}




\begin{tabular}{l|l|l}
\hline 4 & $\begin{array}{l}\text { Alex Haxeltine, Bonno Pel, Julia M. } \\
\text { Wittmayer, Adina Dumitru, Rene Kemp, } \\
\text { and Flor Avelino }\end{array}$ & $\begin{array}{l}\text { Building a middle-range theory of Transformative Social Innovation; } \\
\text { theoretical pitfalls and methodological responses }\end{array}$ \\
\hline 5 & $\begin{array}{l}\text { Christoph Kaletka, Antonius Schröder } \\
\text { A Global Mapping of Social Innovations: Challenges of a Theory } \\
\text { Driven Methodology }\end{array}$ \\
\hline 6 & $\begin{array}{l}\text { Katharine Albertine McGowan, Frances } \\
\text { Westley }\end{array}$ & $\begin{array}{l}\text { Constructing The Evolution of Social Innovation: Methodological } \\
\text { Insights from a Multi-Case Study }\end{array}$ \\
\hline 7 & $\begin{array}{l}\text { Bonno Pel, Jens Dorland, Julia M. M. } \\
\text { Wittmayer, Michael S. Jørgensen }\end{array}$ & $\begin{array}{l}\text { Detecting Social Innovation Agency: Methodological reflections on } \\
\text { units of analysis in dispersed transformation processes }\end{array}$ \\
\hline $\begin{array}{l}\text { Francesca Rizzo, Alessandro Deserti, Onur } \\
\text { Cobanli }\end{array}$ & $\begin{array}{l}\text { Introducing Design Thinking in Social Innovation and in the Public } \\
\text { Sector: a design based learning framework }\end{array}$ \\
\hline
\end{tabular}

\section{The normative dimension: Translating axiological positions in method choices}

Axiological standpoints include ethical considerations, philosophical viewpoints and normative commitments (Dillon \& Wals 2006). As stressed by critical-constructivist scholars, such standpoints inevitably express themselves in method choices as well (Ulrich 2003, Schwartz-Shea \& Yanow 2012). The methodological challenges of handling this normative dimension are particularly important for SI research. To begin with, there are high hopes for social innovation to empower society and address the big challenges of our time (BEPA 2010). The traditionally strong commitments to developing empowering knowledge have accordingly led to calls for transdisciplinary, action-oriented research methodologies (Arthur 2013, Jessop et al. 2013, Moulaert \& van Dyck 2013, Moulaert et al. 2017). This has involved critical (e.g. Marxist, Feminist) research modes geared to reveal hegemonic structures and to empower the marginalized (cf. Haraway 1988), but also pragmatist quests for actionable knowledge (Moulaert \& Mehmood 2013, cf. Greenwood and Levin 2007) and transdisciplinary efforts towards co-production of real-world knowledge (Novy et al. 2013; cf. Hirsch Hadorn et al. 2008, Lang et al. 2012). However, while it is easy to discern how normative commitments are methodologically translated in these cases, also less activist methodological approaches can be retraced to normative commitments and axiological standpoints. There is also the realist-positivist stance of striving for transparent, objective and impartial knowledge (Payne \& Payne 2004), with the normative commitment to open, rationallyguided societies as brought out passionately by the Vienna circle and Karl Popper (Popper 2012). Such commitment to 'sound science' gains normative significance in the light of the earliermentioned ideological dimensions of the SI concept, and in the light of the as yet highly uncertain impacts of SI. Finally, there are the neither activist nor objectifying approaches that stress the performativity of methodology choices. Researchers in the tradition of STS and interpretive analysis consider that choices of demarcation, sampling and narrative presentation order and 'enact' 
social realities (Law 1992, Wagenaar 2011, Asdal \& Moser 2012). Any mode of observation highlights some aspects of SI phenomena and backgrounds others. These representations are not innocent, as they create expectations, 'brands' and narratives of SI that cast some as innovation heroes and others as bystanders or 'incumbent' actors.

These three axiological positions can all be found in the contributions to this special issue. Three contributions clearly call for transdisciplinary, action-oriented research. Biekart (2017) focuses on civic innovation, which as "creative forms of cultural, political and economic resistance and pathways to social change" implies a politically more articulate concept than social innovation. He argues that research on civic innovation needs to be critical and contribute to the generation of knowledge "that embodies progressive social change". The key methodological challenge that arises from this commitment is to make the plurality of the voices of those involved in civic innovation heard. For this end, the author suggests participatory action research. Arguing for the same kind of method, Aiken (2017) starts from the premise that in order to understand the concept of community and assess its role in social innovation, it is necessary to have access to community and to focus on what is happening within these groups. Less in the tradition of critically questioning hegemonic structures but along the lines of aiming to bring about positive social change, Rizzo et al. (2017) consider the public sector to require public and social innovation to better meet the needs of citizens and end users. Co-creation and especially design thinking methodologies are proposed to guide processes of learning-by-doing and real-world experimentation - where understanding and changing the world come hand in hand.

A quest for more sound science is a research stance that is recognizable in Callorda et al. (2017). The authors identify the contested nature of the social innovation concept as a methodological challenge for sampling. They propose Delphi as a consensus-based method for arriving at more conceptual clarity (i.e. decontestation). It allows them to capture the perceptions of a group of experts about what can be identified as social innovations in domiciliary elderly care. Through different iterations, 42 social innovation cases were identified. After subsequent sorting, the authors used the selected sub-set for a multi-case analysis. Similarly, McGowan \& Westley (2017) are navigating the space between the methodological innovation needed to grasp social innovation and "maintaining a degree of replicability and theoretical coherence which help contribute to an emerging field of study". In choosing for a longitudinal multi-case comparison design, they confront the fact that in general SI research focuses on theory refinement or exploration rather than on validation or testing. Related to this commitment to tested knowledge, they also warn against resignation into the theoretical fragmentation in the field, and against researchers working within their specific community rather than transcending it.

Two contributions stand out in how they relate to performativity of knowledge. Pel et al. (2017) address the normative dimension as an issue that pervades research and methodology, which resides in the slicing up, framing, stylizing, casting and 'enacting' of social reality that happens when analyzing and categorizing. The article focuses on the performativity of units of analysis choices. Evaluating the upsides and downsides of the relational approach taken to this issue, the 
authors recommend that "[i]t is therefore worthwhile to develop methodologies in which the principal SI agents are not presupposed, acknowledging that they are often yet to be detected." Finally, the performativity of method choices becomes particularly evident in the global mapping described by Kaletka \& Schröder (2017). The associated crafting of an SI Atlas clearly reflects the rather activist normative commitment to support the emancipation of SI actors as innovative actors (Cf. section 1). On the other hand, the authors also show the positivist objectifying research ethos, critically discussing the procedures through which to arrive at a truthful and balanced map. Their concern for their selective exposure of SI initiatives shows a performativity issue that is particularly relevant to SI research: After all, a prominent part of SI initiatives' strategies consists in efforts towards 'putting themselves on the map'.

\section{The temporal dimension: The need for time-sensitive methodologies}

A fundamental methodological challenge for SI research is the difficulty to account for the process character of social innovation (Mulgan 2006), apparent through the common understandings of SI in terms of dynamic innovation journeys (Van de Ven et al. 2008). As matter of consistency this process character requires accordingly process-oriented methodologies. Beyond this general appreciation of innovation dynamics, however, the temporality of SI involves several more specific considerations.

First of all, like any innovation, SI involves processes of becoming (Pettigrew 1997). The novel practices, services, and social relations typically change over time and exist in different states of maturation and adaptation to their surroundings. As stressed by Akrich et al. (2002), retrospective explanations typically miss out on the coordination efforts, contestations and setbacks experienced by situated actors. They recommend methods geared to follow innovation-in-themaking, abstaining from after-the-fact rationalizations. Second, the path dependency of SI practices has already been argued through various accounts of cyclical institutional renewal (Moore et al. 2012), contextual re-emergences (Moulaert \& Ailenei 2005) and epochal shifts such as the rise of the service economy (Howaldt et al. 2015) or New Public management (Lévesque 2013). Finally, it is methodologically challenging that the SI concept itself is historically evolving. In line with the critical innovation theory proposed by Godin \& Vinck (2017), current SI cannot be understood through the notions of social innovation that emerged in the early $18^{\text {th }}$ century (Moulaert et al. 2017, Ayob et al. 2016). In current innovation society, the concept has become part of a widely spread societal discourse in which innovation is a principal mode of bringing about societal change. These three aspects of SI temporality underline the point made by Garud \& Gehman (2012): For lack of a singular catch-all process method, it is important to tailor approaches that elicit particular aspects of innovation journeys.

Within the set of featured articles, the main frontier seems to be the development of evolutionary explanation. McGowan \& Westley (2017) convincingly argue how this could clarify the key process-theoretical questions on the "emergence, growth and normalization" of SI. Moreover, their historical approach strikes at the heart of SI conceptualization, as it searches for the 
SI counterparts to the seminal, innovation-sparking technologies as theorized in evolutionary economics. Emphasizing how historical case studies imply researching SI before it was known and acknowledged as such, they raise the important methodological issue that 'natural' SI cases do not exist: Their cases on amongst others societal introduction of national parks, birth control policies and financial derivatives do not clearly fall into the current categorizations of what is and isn't SI.

The above search for evolutionary understanding is shared by the contribution of Haxeltine and colleagues (2017). They reconstructed social innovation 'journeys' so as to explain how social innovation initiatives can have broader transformative impacts. Yet, their research was driven more explicitly by the aim to develop 'empowering' insights that could inform situated SI initiatives. Accordingly, the latter focused on SI journeys of contemporary SI initiatives. This entailed a relational rather than an evolutionary investigation of innovation journeys (Garud \& Gehman 2012), geared towards the contested arenas and co-production dynamics of SI in-the-making. As also addressed in Pel et al (2017), the choice of either studying evolutionary pathways or innovation inthe-making has implications for the research design. While the former requires archive research for data gathering, the latter relies on in-depth interviews and (participative) observation. A highly relevant practical circumstance resides in the relatively limited institutional memories of the SI initiatives under study.

However obvious the need for evolutionary accounts, a longitudinal comparison of SI 'pathways' is not the only way to methodologically account for temporality. As already mentioned, the practical concern for empowering insight commits many researchers to modes of investigation in which the researchers seek to capture the uncertainties and passions of innovation journeys 'from within'. Such approaches are taken in the contributions by Aiken (2017) and Biekart (2017), whose commitments to participatory action research involve phenomenological approaches to SI in-themaking that challenge distanced accounts of SI pathways and system transitions. Also Mc Gowan \& Westley (2017) and Haxeltine et al. (2017) express concerns with these objectivistic shadow sides of evolutionary process explanations: who observes whose SI journey? Whose journey narrative counts?

Apart from the phenomenological and relational commitments to in-depth immersion in SI in-the-making, the prominent practice orientation in SI research also brings forward experimental approaches. The contribution by Rizzo et al. (2017) exposes how real- world-experiments can engender processes of collective learning-by-doing. These experiments with new social relations crucially involve iterations between practical intervention and reflection; they are methodologies for both management and research. It is the iterative character of experimentation that plays into the temporality of SI. Experiments start from the premise that outcomes of SI processes cannot be known beforehand, that interactions between SI experiments and their selection environment must be followed, and that SI is a process that may take several rounds of interventions before it manifests. Interestingly, the described experiment with co-creating individuals and organizations also yielded concrete evidence on the path-dependent historical contexts that SI initiatives tend to run up against. The authors identify fragmentation over organizational silos and lack of 
acquaintance with user perspectives as persistent barriers to the participatory governance modes that they deem needed.

The latter example of historically formed inertias as encountered during an experiment summarizes it in a nutshell: SI research needs time-sensitive methodologies that help to understand SI in terms of dynamic innovation journeys, but especially needs to be supported by methodological reflections on the different temporalities involved. Social innovation journeys can be reconstructed through various demarcations and narrative perspectives.

\section{The comparative dimension: Broadening, deepening and sampling}

One of the main critiques on the current state of SI research is its overreliance on 'unique case' or few-case research designs. For consolidating the SI research field, it may be imperative to resolve its own 'case study crisis' (Yin 1981), and move towards systematic comparison of SI cases. Apart from the academic interest as articulated by Bouchard \& Trudelle (2013), also practitioners and policy-makers are seeking a more solid evidence basis for SI practice (European Commission 2013: 7). The development of successful scaling strategies and overviews (Pelka \& Terstriep 2016) arguably call for a broadening of the investigative scope - not only through evolutionary theorizing of meso- and macro levels (Cf. section 3), but also in terms of larger numbers of cases. On the other hand, the deepening of the evidence base seems no less important since the SI concept is yet to be figured out. Such conceptual clarification relies strongly on the availability of paradigmatic cases (Flyvbjerg 2006). The calls for single-case deepening are reinforced through participatory action research and phenomenological approaches, typically providing the 'life-world'-understandings of SI initiatives that they consider underrepresented. Throughout these considerations of broadening and deepening, there is an important third concern, however: Any broadening towards larger-N research would have to confront difficulties of sampling and harmonized case demarcations.

Three contributions describe research endeavours at the forefront of the aforementioned 'move beyond anecdotal evidence'. Kaletka \& Schröder (2017) pay a particularly strong tribute to the comparative ambitions of SI research. Their worldwide mapping of SI initiatives features no less than 1005 cases. Just like Haxeltine et al. (2017) - working with about a hundred cases of 'local SI initiatives' - they seek to achieve both a broadening and deepening of the evidence basis, combining qualitative and quantitative approaches. Both contributions show that SI theory-building requires iterative research designs, ensuring stepwise refinement of theoretical understanding. These iterations - the two contributions involve instructive differences in the sequences of research phases - crucially respond to the current state of SI theory. There is no well-established SI theory to test, but rather a cluster of SI understandings to explore and elaborate. These efforts towards broadening of the evidence basis are not only about 'increasing the N'. Geared to explore empirical diversity, they are about deepening as well. The latter point speaks particularly clearly from McGowan \& Westley (2017). Their collective study of eight cases displays strong ambitions towards generalization and theory-building, yet also the ambition to explore and refine theoretical intuitions through the cases. Finally, the above three contributions deliberately work with embedded cases and 
units of analysis, thereby reminding us of the multiple cases that may be carved out within (composite) cases.

When even such multiple case or survey-like mappings acknowledge the need for deepening, it serves to remind why SI research is so particularly strongly attached to single-case studies. Several contributions assert the sustained relevance of the single case study as a way to attend to the particularities of SI action systems in a holistic way. As underlined by Pel et al. (2017), the very categories of SI actors, initiatives, networks or 'ecosystems' have yet to be elaborated. Describing the complexity of investigating rather fluid and multiply intertwined actor networks, the authors explicitly address the trade-offs between single-case deepening and comparative broadening. They remind that it is not only a question of how much embeddedness and fluidity research designs can afford regarding their units of analysis, but also a matter of how much they need. In line with these relationist cautions against unwarranted reification and oversimplification, Aiken (2017) provides further principled arguments for unique-case research. Seeking to understand community as both a means and an end of social innovation, Aiken (2017) argues for small-scale approaches, and specifically for modes of participatory action research as they allow researchers to understand "the constitutive experience of community, the affective bonds and drivers that provoke or forestall action, and what any such community action is like, from the inside". The latter emphasis on the importance of 'inside' experiences and understandings is also given in Biekart (2017): To take the quest for new social relations seriously, is also to reconsider established relations between observers and observed.

Finally, this special issue also reflects various confrontations of the as yet largely unknown 'universe of SI cases'. Taken up as a methodological challenge, this takes the well-rehearsed debate about conceptual ambiguity significantly further. The most elaborate account of the associated challenges and advances is provided by Callorda et al. (2017). They discuss how the sampling of SI initiatives can be grounded in the existing diversity of SI discourses through careful Delphimethod procedures. Based on an iterative design and steered by a transdisciplinary group, invited experts identified social innovation cases, and subsequently sorted them out into a final sample of fifteen cases. The procedure successfully addressed sampling challenges including conceptual ambiguity, normativity of researchers and positive valuation dependent upon knowledge about a case. The issue of sampling is also critically confronted by McGowan \& Westley (2017), who instructively indicate how their research group selected and discarded presumed 'cases' from their theoretically defined set. Particularly worthwhile are the reflections of Kaletka \& Schröder (2017) on their ambitious attempt at comprehensive mapping: ".., due to the ongoing and rapid development and the high variety of social innovation activities it is doubtful if a statistically representative research is feasible and desirable. Neither a complete inventory of the whole population nor statistical representative samples seem to be feasible yet. The basic population in its outreach may remain statistically unknown because of the constant changes of the initiatives (not persons are the main unit but initiatives /projects)." This does not mean that the authors argue against the relevance of survey methods to SI research, however. It rather reflects how these 
contributions on SI sampling prepare the ground for systematic, well-considered broadening of the SI evidence basis - asking basic but urgent questions about what an SI case comprises.

\section{Conclusion: Towards reflexive SI research}

A mature field of research presupposes not only conceptual clarity, but also thorough consideration of methodologies and logics of inquiry through which knowledge is developed. This special issue attends to the latter, hitherto rather neglected aspect of SI research. Its contributions share a concern with coherent logics of inquiry and methodology choices, more often than not led by particular research aims rather than by principled preferences. They discuss particular methodological challenges and advances and embed these in broader quests for methodological coherence. The special issue provides a reasonably comprehensive overview of the current state of methodological reflection since the contributions cover the main methodological orientations in SI research, namely systematic knowledge development and action-oriented research.

This editorial synthesis serves to take stock of the main methodological challenges identified and the advances proposed by the different contributions. To elicit their broader significance for SI research, we identified three transversal themes that run through the entire set of featured contributions. These constitute three dimensions of methodology choices, which are salient to SI research, without being tied to any specific methodological tradition. As such, they reflect our aim to transcend the methodological fragmentation and open up a methodological discussion through a methodologically pluralist stance.

Regarding the normative dimension of methodology choices; its pervasiveness for any SI research has become apparent. Common juxtapositions of engaged versus detached and critical versus positivist science do not hold, especially where they suggest a choice between normative and neutral modes of inquiry. Instead, the featured contributions have highlighted various concrete research practices that translate the normative commitments of the researchers, such as using a consensus-based method to arrive at a balanced sample, the use of action-oriented research to allow for counter-hegemonic knowledge production and the use of as fluid units of analysis as needed.

Regarding the temporal dimension; contributions appear to share the need to study SI consistently as process of becoming. In line with the general move in innovation studies towards reconstructing innovation journeys, the special issue contains several contributions proposing methods to capture the temporality of SI journeys. In this regard, there are not only proposals for evolutionary analysis and for study of innovation in-the-making; real-life experimenting constitutes a methodological advance that radicalizes the idea that the temporality of SI needs to be experienced.

Regarding the comparative dimension; the classic debate between qualitative and quantitative is flaring up within SI research. Taken together, the featured contributions bring forward interesting, sometimes principled, arguments for both single case deepening as well as for larger-N broadening of the SI evidence basis. The move towards embedded-case set-ups stresses the 
multiplicity within cases. Particularly promising are the various ways in which contributors confront the challenges of sampling as well as studying an ambiguous, intermittent and dynamic phenomenon.

In putting the topic of methodology and logics of inquiry explicitly on the agenda of SI research, we hope to contribute to a further consolidation of the field. The set of featured articles reminds however that this is not to be confused with methodological standardisation. Our methodological pluralist stance appreciates that SI theory is still in statu nascendi, that different aspects of SI phenomena require different methodological approaches and tools. The emphasis on consistent logics of inquiry thus refrains from elevating either engaged participatory action research, solidifying surveys or politically aware critical modes of inquiry into methodological benchmarks.

Still, this editorial synthesis does sketch particular directions for SI research. The very sample of contributions and the identification of transversal themes obviously reflects certain preferences and convictions. We have highlighted the particular importance of new modes of action-oriented research, as ways to undertake efforts towards changing social relations, also within research practice. Alongside, we have emphasized the importance of reflexive methodology development (accounting for the -changing - position of the researcher) and of critical methodologies (inquiring and self-inquiring how constructions of SI cases reflect assumptions about what SI is and should be). Another set of recommendations is in line with the insistence of Moulaert and colleagues (2017) on continuity and historical awareness in SI research. For the SI research field to consolidate beyond the loose sequences of fast-science and inward-looking projects, much is to be said for at least taking on board earlier methodological innovations in adjacent fields. In this regard we highlighted the relevance of process-oriented methodologies (studying SI seriously as processes of becoming), explorative methodologies (taking the theoretical state of the field as a challenge), and ambitious methodologies (reaching for generic insights and a degree of overview into the so particularly elusive 'universe of SI cases'). 


\section{References}

Aiken, G.T. (2017). Social Innovation and Participatory Action Research: A way to research community? European Public and Social Innovation Review 2: 1.

Akrich, M., Callon, M., Latour, B., and Monaghan, A. (2002). The key to success in innovation part I: the art of interessement. International Journal of Innovation Management, 6(02), 187-206.

Arthur, L. (2013). Reflections on the form and content of Participatory Action Research and implications for social innovation research. In: Moulaert et al. (eds.), The International Handbook on Social Innovation: Collective Action, Social Learning and Transdisciplinary Research ( pp. 332340, Ch. 25). Cheltenham: Edward Elgar Publishing

Asdal, K. and Moser, I. (2012). Experiments in context and contexting. Science, Technology, \& Human Values, 37(4), 291-306.

Ayob, N., Teasdale, S. and Fagan, K. (2016). How Social Innovation 'Came to Be': Tracing the Evolution of a Contested Concept. Journal of Social Policy,45(4), 635-653. doi:10.1017/S004727941600009X

BEPA (Bureau of European Policy Advisors) (2010) Empowering people, driving change. Social Innovation in the European Union. Brussel: European Commission.

Biekart, K. (2017). Contributing to Civic Innovation through Participatory Action Research. European Public and Social Innovation Review 2: 1.

Blatter, J., and Haverland, M. (2012). Designing case studies: Explanatory approaches in small-N research. Basingstoke: Palgrave Macmillan.

Bouchard, M.J. and Trudelle, C. (2013). Exploring the conceptual universe of social innovation: A relational database for a better understanding of its effects on social transformation, (Paper presented at the international conference Social Frontiers : The next edge of social innovation research, at GCU's London Campus on 14th and 15th November 2013).

Cajaiba-Santana, G. (2014). Social innovation: Moving the field forward. A conceptual framework. Technological Forecasting and Social Change, 82, 42-51.

Callorda Fossati, E., Degavre, F., and Nyssens, M. (2017). How to deal with an "essentially contested concept" on the field? Sampling social innovations through the Delphi method. European Public and Social Innovation Review

Dillon, J. and Wals, A. (2006).On the danger of blurring methods, methodologies and ideologies in environmental education research, Environmental Education Research, 12:3-4, 549-558

Edwards-Schachter, M. and Wallace, M.L. (2017). 'Shaken, but not stirred': Sixty years of defining social innovation. Technological Forecasting and Social Change, 119, 64-79. 
El-Haddadeh, R., Irani, Z., Millard, J. and Schröder, A. (2014). Toward a Coherent Methodological Framework for Examining Social Innovation in the Public Sector. Information Systems Management, 31(3), 250-258.

EUROPEAN COMMISSION (2013) Social innovation research in the European Union Approaches, findings and future directions. POLICY REVIEW. Luxembourg: Publications Office of the European Union.

Flyvbjerg, B. (2006). Five misunderstandings about case-study research. Qualitative inquiry, 12(2). 219-245.

Franz, H. W., Hochgerner, J., and Howaldt, J. (2012). Challenge social innovation: An introduction. In Challenge Social Innovation (pp. 1-16). Berlin, Heidelberg: Springer

Garud, R., and Gehman, J. (2012). Metatheoretical perspectives on sustainability journeys: Evolutionary, relational and durational. Research Policy 41(6). 980-995.

Godin, B., and Vinck, D. (2017). Critical Studies of Innovation: Alternative Approaches to the ProInnovation Bias. Cheltenham: Edward Elgar

Haraway, D. (1988). 'Situated Knowledges: The Science Question in Feminism and the Privilege of Partial Perspective', Feminist Studies 14(3). 575-599.

Haxeltine, A., Pel, B., Wittmayer, J., Avelino, A., Dumitru, A. and Kemp, R. (2017). Building a middle-range theory of Transformative Social Innovation; theoretical pitfalls and methodological responses. European Public and Social Innovation Review 2: 1.

Hirsch Hadorn, G., Hoffmann-Riem, H., Bieber-Klemm, S., Grossenbacher-Mansuy, W., Joye, D., Pohl, C., Wiesmann, U. and Zemp, E. (2008). Handbook of Transdisciplinary Research. Dordrecht: Springer.

Howaldt, J., Kopp, R., and Schwarz, M. (2015) On the theory of social innovations: Tarde's neglected contribution to the development of a sociological innovation theory. Weinheim : Beltz Juventa, 2015. URN: http://nbn-resolving.de/urn:nbn:de:0168-ssoar-41963

Jessop, B., Moulaert, F., Hulgård, L. and Hamdouch, A. (2013). Social innovation research: a new stage in innovation research? In: Moulaert, F. et al. (eds.). The International Handbook on Social Innovation: Collective Action, Social Learning and Transdisciplinary Research. (110-127) Cheltenham: Edward Elgar

Jungmann R., Baur, N. and Ametowobla, D. (2015). Grasping Processes of Innovation Empirically. A Call for Expanding the Methodological Toolkit. An Introduction. Historische Sozialforschung/ Historical Social Research (HSR). 7-29.

Kaletka, C. and Schröder, A. (2017). A Global Mapping of Social Innovations: Challenges of a Theory Driven Methodology. European Public and Social Innovation Review 2: 1. 
Lang, D. J., Wiek, A., Bergmann, M., Stauffacher, M., Martens, P., Moll, P. and Thomas, C. J. (2012). Transdisciplinary research in sustainability science: practice, principles, and challenges. Sustainability science, 7(1), 25-43.

Larsson, O.S. and Brandsen, T. (2016). The Implicit Normative Assumptions of Social Innovation Research: Embracing the Dark Side. In: Brandsen et al. (eds), Social Innovations in the Urban Context. (pp. 293-302, Ch. 24). New York: Springer.

Law, J. (1992). Notes on the theory of the actor-network: Ordering, strategy, and heterogeneity. Systemic practice and action research. 5(4). 379-393.

Lévesque, B. (2013) Social innovation in governance and public management systems: towards a new paradigm? In: F. Moulaert (Ed.), The International Handbook on Social Innovation; Collective Action, Social Learning and Transdisciplinary Research, Edward Elgar, Cheltenham, 2013.

Marques, P., Morgan, K., and Richardson, R. (2017). Social innovation in question: The theoretical and practical implications of a contested concept. Environment and Planning C: Politics and Space, 2399654417717986.

Martinelli, F., Moulaert, F and González, S. (2010). Creatively designing urban futures: A transversal analysis of socially innovative initiatives. In: Moulaert et al., (eds) Can neighbourhoods save the city? Community development and social innovation. (pp. 198- 218, Ch. 14) London: Routledge.

McGowan, K. and Westley, F. (2015). At the Root of Change: The History of Social Innovation. In: Nicholls, A. et al., (eds), New Frontiers in Social Innovation Research (pp. 52-68, Ch. 3). Basingstoke: Palgrave Macmillan

McGowan, K.A. and Westley, F. (2017). Constructing the Evolution of Social Innovation: Methodological Insights from a Multi-Case Study. European Public and Social Innovation Review 2: 1 .

Moore, M. L., Westley, F. R., Tjornbo, O., \& Holroyd, C. (2012). The loop, the lens, and the lesson: using resilience theory to examine public policy and social innovation. In Nicholls \& Murdock (2012), Social innovation (pp. 89-113). Palgrave Macmillan UK.

Moulaert, F and Van Dyck, B. (2013). Framing Social Innovation Research: a Sociology of Knowledge Perspective in Moulaert, F. et al. (eds.). (2013). The International Handbook on Social Innovation; Collective Action, Social Learning and Transdisciplinary Research (pp. 466-479) Cheltenham: Edward Elgar

Moulaert, F. (2010). Social innovation and community development: concepts, theories and challenges. In: Moulaert et al., (eds) Can neighbourhoods save the city? Community development and social innovation. (pp, 4-16, Ch1) London: Routledge. 
Moulaert, F. and Mehmood, A. (2013) Holistic research methodology and pragmatic collective action. In: Moulaert, F. et al., (eds) The International Handbook on Social Innovation: Collective Action, Social Learning and Transdisciplinary Research (pp. 442-452, Ch. 33). Cheltenham: Edward Elgar

Moulaert, F. Mehmood, A, MacCallum, D. and Leubolt, B. (Eds.) (2017). Social Innovation as a Trigger for Transformations; The Role of Research, European Commission, Directorate-General for Research and Innovation

Moulaert, F., and Ailenei, O. (2005). Social economy, third sector and solidarity relations: A conceptual synthesis from history to present. Urban studies. 42(11). 2037-2053.

Mulgan, G. (2006). The process of social innovation. Innovations, 1(2), 145-162.

Murray, R., Caulier-Grice, J. and Mulgan, G. (2010). The open book of social innovation. London: National endowment for science, technology and the art.

Novy, A., Habersack, S and Schaller, S. (2013). Innovative forms of knowledge production: transdisciplinarity and knowledge alliances. In: Moulaert, F. et al. (eds.). The International Handbook on Social Innovation: Collective Action, Social Learning and Transdisciplinary Research. (pp. 430-441, Ch. 32) Cheltenham: Edward Elgar

Osburg, T. and Schmidpeter, R. (2013). Social Innovation. Solutions for a sustainable future. Berlin Heidelberg: Springer.

Payne, G. and Payne, J. (2004). Sage key Concepts: Key concepts in social research London: SAGE Publications. DOI: 10.4135/9781849209397

Pel, B., Dorland, J., Wittmayer, J.M. and Jørgensen,M.S. (2017). Detecting Social Innovation Agency: Methodological reflections on units of analysis in dispersed transformation processes. European Public and Social Innovation Review 2: 1.

Pelka, B., and Terstriep, J. (2016). Mapping the Social Innovation Maps-The State of Research Practice across Europe. European Public and Social Innovation Review, 1(1). 3-16.

Pettigrew, A. M. (1997). What is a processual analysis? Scandinavian Journal of Management. 13(4), 337-348.

Pol, E., and Ville, S. (2009). Social innovation: Buzz word or enduring term?. The Journal of SocioEconomics, 38(6), 878-885.

Popper, K. (2012). The open society and its enemies. Routledge.

Rizzo, F., Deserti, A. and Cobanli, O. (2017). Introducing Design Thinking in Social Innovation and in the Public Sector: a design based learning framework. European Public and Social Innovation Review 2: 1. 
Schröder, A., Weerakkody, V., El-Haddadeh, R., Kapoor, K., Butzin, An., Boelman, V., Scoppetta, A., Weber, M., Schaper-Rinkel, P., Dhondt, S. and Oeij, P. (2014). Methodology Review: Research Propositions, Data Collection and Analysis Framework. Deliverable 2.1 SI-DRIVE Grant Agreement 612870.

Schubert, C. (2017), Social Innovation; a New Instrument for Social Change?, in Rammert, W, et al. (eds.), Innovation Society Today. Heidelberg: Springer Verlag, 371-391

Schwartz-Shea, P. and Yahow, D. (2012). Interpretive Research Design. Concepts and Processes. New York and London: Routledge.

Ulrich, W. (2003). Beyond methodology choice: critical systems thinking as critically systemic discourse. Journal of the Operational Research Society, 54(4). 325-342.

Van de Ven, A. H., Polley, D., \& Garud, R. (2008). The innovation journey. Oxford University Press, USA.

Van der Have, R.P. and L. Rubalcaba (2016). Social Innovation research: An emerging area of innovation studies? Research Policy 45: 1923-1935

Venn, L., Kneafsey, M., Holloway, L., Cox, R., Dowler, E., and Tuomainen, H. (2006). Researching European 'alternative' food networks: some methodological considerations. Area, 38(3). 248-258.

Voß J.-P. \& Freeman R. (2016). Introduction: Knowing Governance, In: Voß JP \& Freeman R (Eds.) (2016) Knowing Governance: The Epistemic Construction of Political Order. Basingstoke: Palgrave Macmillan, 1-34

Wagenaar, H. (2011). Meaning in Action. Interpretation and Dialogue in Policy Analysis. London: M.E. Sharpe.

Yin, R. K. (1981). The case study crisis: Some answers. Administrative science quarterly, 26(1). 5865 . 